\title{
Drive-in steel storage racks I: Stiffness tests and 3D load transfer mechanisms
}

\author{
Dr Benoit P. Gilbert ${ }^{(1)}$ \\ Prof. Kim J.R. Rasmussen ${ }^{(2)}$ (M. ASCE)
}

(1) Formerly, PhD student, School of Civil Engineering, The University of Sydney, NSW 2006, Australia. Present, Lecturer, School of Engineering, Griffith University, QLD, Australia.

(2) Professor, School of Civil Engineering, The University of Sydney, NSW 2006, Australia.

\begin{abstract}
Steel storage racks, made of cold-formed steel, are used extensively in industry for storing goods. Two main racking systems prevail, referred to as "selective" and “drive-in” racks. International racking design codes mainly deal with selective racks, while limited design guidelines are available for drive-in racks. Drive-in racks require minimum floor space by storing pallets one after the other with no space between them. The forklift truck drives into the rack to store the pallets on the first-in, last-out principle. To allow forklift passage, drive-in racks can only be braced at the back (spine bracing) and at the top (plan bracing) in the down-aisle direction resulting in a complex slender structure with poorly understood 3D behavior and increased risk of collapse. As yet, tests on drive-in rack systems to accurately capture their 3D behavior are not available in the literature. This paper presents experimental results from full-scale tests conducted on a complete drive-in rack system. Experimental investigations of the load transfer and
\end{abstract}


relative stiffness under various horizontal loading conditions are presented. Experiments have been performed on loaded and unloaded racks.

Keywords: Steel storage racks, Drive-in racks, 3D behaviour, Load transfer, Fullscale tests. 


\section{Introduction}

Worldwide, steel storage racks are used in industry for storing goods on pallets. They are freestanding and act as structures in their own right. Storage racks are designed to carry pallet loads and to resist placement and impact forces from forklift trucks. They are heavily loaded and designed as lightly as possible in the prevailing competitive industry. Different types of racks are available on the market and are described in Pekoz and Winter (1973). “Selective racks”, the most common type of rack, are separated by aisles and each pallet is always accessible. On the other hand, “drive-in racks", require less floor space by storing pallets on rail beams, one after the other, with no space between them. The forklift truck drives into the rack to store the pallets on the first-in, last-out principle. With the increasing price of land, drive-in racks are a more economical solution to selective rack when storing the same good.

To allow forklift passage, drive-in racks can only be braced at the back (spine bracing) and at the top (plan bracing) in the down-aisle direction. Uprights have then substantial unbraced lengths and are prone to buckling in the down-aisle direction. Driveracks can typically be 3 to 7 pallets deep resulting in a complex slender structure with poorly understood 3D behaviour and increased risk of collapse.

This paper forms part of a research program investigating the strength and behaviour of drive-in racks subject to horizontal impact forces caused by the accidental collision of forklift trucks entering or exiting the rack. The present paper focuses on understanding the 3D behaviour, while the companion paper (Zhang, et al., 2011) presents a reliability-based methodology for designing drive-in racks against impact. 
The main racking design codes, Rack Manufacturers Institute Specification (RMI, 2008), European code (EN 15512, 2009) and Australian Standard (AS 4084, 1993) only apply to selective racks and not to drive-in racks. The Storage Equipment Manufacturers' Association Code of Practice (SEMA, 1980) mentions drive-in racks but is not explicit. A European code for drive-in racks (FEM 10.2.07, 2002) is currently being developed but not available yet.

In the literature, very few tests have been performed on drive-in racks and were mainly conducted on parts of the structure (Murray, 1995), shallow racks (Freitas, et al., 2006, 2007) or compact systems (Dunai, et al., 1997). These tests investigated the ultimate capacity of the racks and loads were mainly applied vertically by means of reaction frames. Therefore, tests on a complete system to accurately capture the rack $3 \mathrm{D}$ behaviour are currently not available. Additionally, it is likely that pallets have a significant influence on the rack behaviour by acting as horizontal bracing members (Salmon, et al., 1973) and this interaction between the various elements of the structure has to be taken into account when investigating the 3D structural behaviour.

Few theoretical studies of drive-in rack behaviour are available ((Salmon, et al., 1973); (Godley, 2002); (Hua and Rasmussen, 2006)), and results arising from these studies have not been confirmed experimentally.

This paper presents an experimental test set-up and results of tests performed on a complete drive-in rack subjected to horizontal loads. The effect of different spine and plan bracing configurations on the stiffness of the rack is presented for a loaded and an unloaded rack. The rack 3D behavior is explained through an extensive set of measurements of horizontal displacements in the down- and cross-aisle directions. 
Bending moments and axial forces in uprights are recorded using strain gauges and presented in this paper. Additionally, tests are performed to quantify the bracing affect of pallets.

A finite element model of drive-in racks is introduced and shown to accurately reproduce the 3D behavior of the tested rack. Further calibration of the model against dynamically loaded tests is presented in (Gilbert, et al., 2009). Based on the tests and finite element analysis, the companion paper (Zhang, et al., 2011) presents the derivation of a reliability-based design methodology for drive-in racks subjected to horizontal impact loads.

\section{Experimental set-up}

\section{Rack configuration and design}

To accurately capture the 3D behavior and relative stiffness of a drive-in racking system, a complete rack has been tested. The tested rack is 4 pallets deep, 4 bays wide and 4 stories high (i.e. featuring 3 rail beam levels), corresponding to the following overall dimensions: 4.8 meters deep, 5.9 meters wide and 5 meters high. The tested rack is shown schematically in Figure 1 (a).

A plan view of the tested drive-in rack with associated gridlines is given in Figure 1 (b). Each upright is referenced by the letter and number of the gridlines intersecting at its location. The four bays are referenced as bays $\mathrm{AB}, \mathrm{BC}, \mathrm{CD}$ and $\mathrm{DE}$.

The rack was supplied by Dematic Pty Ltd and corresponds to a currently available commercial drive-in rack. It is designed to carry 2 tons pallet loads using the proprietary software RAD (Dematic, 2006). 
Structural drawings of the tested rack can be found in Gilbert and Rasmussen (2009c).

Table 1 summarizes the main properties of the member sections used.

\section{Test set-up}

2 tons and 1.2 tons concrete blocks placed on wood pallets are used to load the rack in order to reproduce real operating conditions. Only the two middle bays of the rack are loaded during testing. This loading pattern is believed to produce the most critical condition: it allows at least one upright to carry the maximum possible axial load while inducing significant bending moment in at least one upright as a result of the eccentric loading of the rail beams. Six different bracing configurations are tested, representing two spine bracing configurations, two plan bracing configurations and no plan or spine bracing. The different bracing configurations are designed to vary the bracing stiffness. Spine bracing configuration 1 covers one bay while spine bracing configuration 2 covers all four bays. Plan bracing configuration 1 covers one bay while spine bracing configuration 2 covers three bays. Figure 2 shows the overall rack configuration and the critically loaded uprights, and Figure 3 shows the different bracing configurations.

In order to gain an understanding of the relative stiffness of the component frames and bracing systems, the rack is subjected to horizontal forces at various positions by means of a servo-controlled hydraulic jack. First, in order to measure the stiffness of the spine bracing, the jack is aligned with the spine bracing plane so as to apply load to the rear portal beam (upright A4) in the down-aisle direction, shown as "position 1" in Figure 3. Specifically, the load was applied at the intersection of the shear centre plane of the upright and the centroidal plane of the portal beam, see insert in Figure 3 (b). Second, to 
measure the stiffness of the plan bracing, the jack is placed at the front of the rack (rack entry - upright A1), shown as "position 2" in Figure 3. Again, the load was applied at the intersection of the shear centre plane of the upright and the centroidal plane of the portal beam. Tests are performed on a loaded and an unloaded rack allowing a comparison between the two loading conditions.

Two separate nominally identical drive-in racks are tested. Between the two series of tests, the rack was completely dismantled and reassembled using new materials.

In a separate series of tests, to provide an understanding of the influence of pallets on the global behavior of the rack, a rack is loaded with a single 2 tons pallet. The pallet is placed at the front of the second rail beam level of bay 'BC'. The hydraulic jack applies a horizontal load on the fourth front upright (upright B1) at the shear centre plane of the upright and at the loaded beam rail elevation (position 3) as shown in Figure 3. Two stiffness tests are performed, one with Teflon strips inserted between the rail beams and the pallet and one without. The Teflon strips allow the rack to be loaded in identical configurations while substantially reducing the influence of the pallet on the rack behavior in one test.

All tests are performed "statically" at a low jack displacement rate (5 mm/min). A minimum of two load cycles are performed per test for the jack in positions 1 and 2. A total of 26 non-destructive tests (including 12 tests repeated on a nominally identical drive-in rack) have been performed and are summarized in Table 2. In Table 2, the spine bracing configurations are labeled as $\mathrm{Sp} 0, \mathrm{Sp} 1$ and $\mathrm{Sp} 2$, as in Figure 3, and the plan bracing configurations are labeled as $\mathrm{Pl} 0, \mathrm{Pl} 1$ and $\mathrm{Pl} 2$, as in Figure 3. 
To accurately capture the 3D drive-in rack behavior, thirteen LVDTs record displacements in the cross-aisle and down-aisle directions as shown in Figure 4. Five LVDTs record the displacements of the east side uprights (uprights A4 to E4) in the cross-aisle direction at the intersection of the upright and portal beam centerlines. Four LVDTs record the displacements of the uprights on the north side (upright E1 to E4) in the down-aisle direction at the intersection of the upright shear centre line and the portal beam centerline. Three LVDTs record the displacements of the most critically loaded upright (upright C2) at each rail beam elevation in the down-aisle direction at the upright shear centre line. One LVDT measures the jack stroke.

Additionally, when testing with the jack in position 3 (tests 'Op1Tef' and 'Op1NoTef'), a fourteenth LVDT records the displacement of the front upright C1 in the down-aisle direction at the second rail beam elevation at the upright shear centre line to measure the opening of bay 'BC'. The bay opening is defined as the difference between the measured horizontal displacements of the front the two rail beams where the pallet is located and reflects the possibility of a pallet to "drop through" the rack.

20 strain gauges are used to obtain the axial loads and major axis bending moments at the base plate to floor connection in five uprights (uprights A1 to D1 and upright C2). The strain gauges are located $250 \mathrm{~mm}$ above the floor, this height was deemed to be sufficiently far from the ends of the uprights that boundary effects could be assumed to be negligible and the stress distribution in the section linear. Four strain gauges are used per upright as shown in Figure 4. An additional eight strain gauges record the axial load in four spine and plan bracing members using two diametrically opposed strain gauges on each tubular member, as shown in Figure 4. The strain gauged 
members are the two bracing members located between the floor and the first rail beam level in spine bracing configuration 1 and 2, and the two plan bracing members located between gridlines 1 and 2 (rack entry) in plan bracing configuration 1 and 2 . The calibration of the strain gauged members is reported in Gilbert and Rasmussen (2009c). Figure 5 shows a picture of the complete structure.

\section{Test results and discussion}

\section{Stiffness test results}

Figure 6 (a) and (b) plot the horizontal load against the jack displacement for the jack in position 1 (aligned with the spine bracing) for the three bracing configurations for a loaded and an unloaded rack respectively. It follows that for an unloaded rack, the use of spine bracing in configuration 2 results in a stiffness approximately five times greater than with no spine bracing, measured as the slope of the line connecting the origin with the load point corresponding to the maximum load in the first cycle. For the same bracing configuration, the stiffness of a loaded rack is generally greater than that of an unloaded rack. This is mainly because the base plate rotational stiffness increases with increasing axial load (Godley, 2007). Most likely, the restraining effect of the pallets also increases the stiffness of the rack. However, the resulting stiffness of a loaded and an unloaded rack is similar for the spine bracing in configuration 2 . This is probably because the spine bracing in configuration 2 runs over the full width of the rack thereby effectively reducing the down-aisle displacement of the portal beams and thus the rotation at the base.

Figure 6 (c) and (d) plot the horizontal load against the jack displacement for the jack in position 2 (aligned with the plan bracing) for the three bracing configurations for 
a loaded and an unloaded rack respectively. The stiffness can be seen to increase with increasing plan bracing stiffness. The increase in the base plate rotational stiffness due to the axial load in the uprights and the bracing effect of the pallets can also be noticed. For the same bracing configuration, the stiffness of the loaded rack is always greater than the stiffness of the unloaded rack. However, the stiffness of the loaded rack with no plan bracing is still greater than the stiffness of the unloaded rack with the plan bracing in configuration 1, emphasising the significance of the contribution to stiffness offered by the uprights through their base plate connections and the horizontal bracing restraint of the pallets.

For clarity, only the first series of tests is plotted in Figure 6. Results from the second series of tests are similar to the first series and can be found in Gilbert and Rasmussen (2009c).

\section{Base plate uplift}

The transfer of a horizontal force down through the spine bracing results in tension in one upright and compression in the other, causing the upright in tension to lift off the floor. Base plate uplift was particularly prominent in the test with the jack in position 1 and the spine bracing in configuration 1. Despite being bolted to the concrete floor, deformation of the base plate assembly resulted in an uplift displacement in excess of $5 \mathrm{~mm}$. The uplift stiffness of the base plate is determined in Gilbert and Rasmussen (2009a) and the initial stiffness is found to be $2.23 \mathrm{kN} / \mathrm{mm}$ for the system considered herein. The base plate uplift effect on the behavior of the rack was investigated numerically and, depending on the width of the spine bracing, found to considerably 
influence the cross- and down-aisle displacements of the rack (Gilbert and Rasmussen, 2009b).

\section{$3 D$ drive-in rack behavior}

To understand the 3D behavior of drive-in racks when subjected to horizontal loads, the LVDT readings of horizontal displacements in the down- and cross-aisle directions are plotted in Figure 7 to Figure 12 for all tests included in Table 2 with the jack in positions 1 and 2.

Figure 7 to Figure 9 show the top view deformation with the jack aligned with the spine bracing (position 1) for a loaded and an unloaded rack for each of the three spine bracing configurations. Apart from the difference in the magnitude of the displacements, reflecting the difference in stiffness of the loaded and unloaded racks, different behaviors can be noticed. When unloaded and with the spine bracing in configuration 1 or 2 (Figure 8 (a), (b) and Figure 9 (a), (b)), the front row stays mainly stationary while the rack deforms linearly along the bays under the horizontal load with the maximum displacement occurring at the jack location. When unloaded and with no spine bracing (Figure 7 (a), (b)), the top of the rack is translated and essentially linearly deformed under the horizontal load, with the maximum displacement also occurring at the jack location.

The deformations shown in Figure 8 and Figure 9 essentially describe a rotation of the plan bracing about the centre upright of the front row. It can also be noticed that base plate uplift increases the cross-aisle displacement of the uprights. This effect is particularly evident for the narrow spine bracing (configuration 1) in Figure 8 (b) and (d) at the back corner of the rack (upright E4) where the upright is in tension because of the forces induced in the spine bracing. This effect can also be noticed, but less significantly, 
for the wide spine bracing (configuration 2) in Figure 9 at the back corners (uprights A4 and E4) of the rack.

For a loaded rack, the combined effect of the pallets and the increased base plate stiffness is to reduce the global deformation of the rack, including the rotation of the plan bracing. In this case, the front row does not stay stationary as for an unloaded rack, and there is less difference between the down-aisle displacements of the front and back rows.

Figure 10 to Figure 12 show the top view deformation with the jack aligned with the plan bracing (position 2) for a loaded and an unloaded rack for each of the three plan bracing configurations. For the case of no plan bracing (Figure 10), the back row stays essentially stationary for both the loaded and the unloaded racks while the rack bends in the down-aisle direction. For plan bracing configuration 1 (Figure 11), the back row also stays essentially stationary but the rack deforms more linearly in the down-aisle direction. The additional rigidity provided by the plan bracing in configuration 2 (Figure 12) forces the top of the rack to translate and linearly deform under the horizontal load. In all cases, the maximum displacement occurs at the jack location.

The plan bracing essentially rotates about the central upright of the back row in transferring part of the load applied at the front to the braced back row. The plan bracing rotation is reduced by the bracing effect of the pallets and the increased base plate stiffness when the rack is loaded.

\section{Axial loads and bending moments}

Figure 13 (a) plots the bending moment in upright C2 (most heavily loaded upright) against the jack load for the jack in position 1 (aligned with the spine bracing) for the three spine bracing configurations, and for a loaded and an unloaded rack. Figure 
13 (b) plots the same curves for the jack in position 2 (aligned with the plan bracing). The bending moments plotted in Figure 13 only arise from the horizontal load contribution and do not include initial moments induced by the pallet loading. It follows that the global restraint in the down-aisle direction provided by the increase in bracing stiffness (no spine or plan bracing, to spine or plan bracing in configuration 1, to spine or plan bracing in configuration 2) limits the overall displacement of the rack and consequently the bending of upright C2 for a given loading configuration.

For the same bracing configuration, the stiffness, taken as the bending moment over the jack load, is greater for a loaded rack than for an unloaded rack, reflecting the increase in the rotational stiffness of the base plate with the axial load in the upright.

Figure 14 and Figure 15 plot the axial load in the front uprights (uprights A1 to D1) against the jack load for the jack in position 2 (aligned with the spine bracing) for the plan bracing in configurations 1 and 2, respectively, for a loaded and an unloaded rack. The axial forces plotted in Figure 14 and Figure 15 only arise from the horizontal load contribution and do not include the initial forces induced by the pallet loading. In Figure 14, the plan bracing rotation under horizontal load is observed by the alternating opposite compression and tension in uprights C1 and D1 to which the plan bracing is connected. It is also observed that for a given jack load, the associated axial load is greater for an unloaded rack than for a loaded rack. This effect reflects the larger displacements of the unloaded rack. Similarly to Figure 14, the plan bracing rotation is observed by the alternating opposite compression and tension in uprights A1 and D1 to which the plan bracing is connected in Figure 15. For a given jack load, the axial loads in uprights C1 
and D1 in Figure 14 and in uprights A1 and D1 in Figure 15 are greater for an unloaded rack than for a loaded rack.

For clarity, only the results of the first series of tests are plotted in Figure 14 and Figure 15. Results from the second series of tests are similar and are reported in Gilbert and Rasmussen (2009c).

\section{Influence of pallets on the rack behavior}

Figure 16 shows the bay opening for the jack in position 3 with a single 2 tons pallet placed on the rack as explained in Section "Test set-up”. It follows from Figure 16, that a static friction force of about $2.4 \mathrm{kN}$ is required to mobilize slip at the interface between the pallet and the beam rail, and that this force is not affected by the presence of the Teflon strips. However, when sliding occurs, there is a noticeable difference in the stiffness between the two cases, indicating that the kinetic friction force is substantially lower in the presence of Teflon strips. The measured stiffness is more than three times greater without Teflon strips (measured as the slope of the load vs bay opening curve) following the initial slip. This result illustrates that pallets have a significant impact on the rack behavior and that the effect of pallets needs to be considered to accurately capture the 3D behavior of drive-in racks. Recent tests to determine the static and kinetic coefficients of friction are reported in Hua and Rasmussen (2010).

\section{FE modeling}

Due to the complexity of drive-in racks, influenced among other factors by the non-linear behavior of the portal beam to upright connection (Gilbert and Rasmussen, 2010), the base plate to floor connection (Godley, 2007), the horizontal bracing effect of 
the pallets investigated in Section "Influence of pallets on the rack behavior" and the not well understood shear behavior of upright frames (Sajja, et al., 2006, Sajja, et al., 2008), accurate modeling of drive-in racks using Finite Element analysis is challenging.

An experimental/numerical approach is used herein, in which a finite element model of the tested drive-in rack is created using the commercial software Abaqus (2005) and checked against the presented experimental static tests. The finite element model features:

a) Beams elements, assuming elastic material behaviour. Shear centre eccentricity is considered for all members and warping torsion is considered for the uprights.

b) Non-linear rotational and uplift stiffness for the base plate to floor connections. The rotational stiffness and strength of the connection depend on the axial load in the upright and this relationship was experimentally investigated for a range of axial loads (Gilbert and Rasmussen, 2009a). In the finite element model, an appropriate multi-linear “elastic non-linear plastic" moment-rotation curve is allocated to each base plate taking into account the axial load in the upright. Figure 17 (a) illustrates a typical multi-linear moment-rotation curve for an axial load of $50 \mathrm{kN}$, in which the curve is obtained by performing a linear interpolation between the experimentally tested axial loads. The uplift force $v s$ displacement relationship of the connection was experimentally investigated (Gilbert and Rasmussen, 2009a) and is modeled using a multi-linear "non-linear elastic" curve, as shown in Figure 17 (b).

c) Non-linear rotational stiffness for the portal beam to upright bolted-moment connections. The moment-rotation behaviour of the connection was experimentally investigated (Gilbert and Rasmussen, 2010) and can be broken into three distinct phases, 
as illustrated in Figure 18. The moment-rotation relationship is modeled using a multilinear "elastic non-linear plastic” moment-rotation curve, as shown in Figure 18.

d) Reduced transverse shear stiffness of the upright frames. The transverse shear stiffness of cold-formed steel bolted frames is typically lower than the value obtained from FEA (Sajja, et al., 2006, Sajja, et al., 2008) and, to accurately model this stiffness, experimental testing is recommended by international Specifications (EN 15512, 2009). The axial stiffness of the upright frame diagonal bracings is reduced by a factor of 2.7 in the finite element model based on test results reported in (Gilbert and Rasmussen, 2009a).

e) Horizontal bracing effect of the pallets. As described in Section "3D drive-in rack behavior”, when subjected to a horizontal force in the down-aisle direction, a drivein rack essentially deforms linearly in the down-aisle direction, resulting in each pallet undergoing shear deformation (Gilbert and Rasmussen, 2009b). Similarly, the action of the plan bracing may force one row of upright frame to deform in the cross-aisle direction, also resulting in each pallet undergoing shear deformation. To incorporate this shear deformation, the base of the pallet is modeled using a square mesh of four crossaisle beams and four down-aisle beams and a trial-and-error procedure was used to find an appropriate value for the shear stiffness of the pallet, to be used in the finite element model. Numerical results on the complete drive-in rack system show that a pallet shear stiffness of $325 \mathrm{~N} / \mathrm{mm}$ allows the global behavior of the rack to be accurately modeled (see Figure 19). To complete the model of the pallet base, a perfect "stick-slide" nonlinear frictional behavior with a static friction coefficient of 0.3 is used between the rail 
beams and the pallet in the cross- and down-aisle directions. The static coefficient of friction was evaluated by the "sliding angle” method (Gilbert and Rasmussen, 2009b).

Using second-order geometric non-linear analyses, the finite element model is found to accurately reproduce the 3D behavior of the rack as illustrated in Figure 19 which compares the experimental and numerical displacements of uprights E1 to E4 at the top plan of the rack, in the down-aisle direction, for test 'Pl1Lo' (see Table 2). Full details of the finite element model and comparisons between experimental and numerical results for all tests included in Table 2 are reported in Gilbert and Rasmussen (2009b).

In addition, in order to quantify the impact force developing between a forklift truck and a drive-in rack, the tested racks have been subjected to forklift truck impacts as presented in the companion paper (Zhang, et al., 2011) and (Gilbert, et al., 2009). When modeling the masses of the pallets, the FE model is found to accurately reproduce the observed dynamic 3D behavior of the rack under impact (Gilbert, et al., 2009).

\section{Conclusion}

This paper presents the results of static tests on a complete drive-in rack system. The paper explains the effects of base plate uplift and spine and plan bracing on the deformations, stiffness and internal forces of the rack. The observed 3D behavior of the rack is explained by plotting the down- and cross-aisle displacements of the top plan of the rack. Differences in behavior are observed for the loaded and unloaded racks, caused mainly by the increased stiffness provided by the pallets and the base plates when the rack is loaded. It is also shown that the pallets provide substantial stiffness to the rack. The tests are particularly useful for validating numerical models of drive-in racks. 
A finite element model of the rack is introduced and found to accurately reproduce the observed 3D behavior of the rack. The model is calibrated further against dynamic impact tests in the companion paper (Zhang, et al., 2011) and used, in conjunction with a reliability analysis, to determine nominal impact forces and load factors for the structural design of drive-in racks.

\section{Acknowledgements}

The authors would like to thank Dr Murray Clarke from Dematic Pty Ltd for his comments and for making the Dematic software RAD available. Also thanks to Dr Lip Teh from the University of Wollongong for his comments. The authors gratefully acknowledge the financial support provided by the Australian Research Council through Discovery Project Grant DP0559983.

\section{References}

Abaqus (2005). Abaqus ver. 6.5-4 - User manual, ABAQUS, Inc., Providence, U.S.A.

AS 4084 (1993). "Steel storage racking." Standards Australia, Sydney, Australia.

Dematic (2006). RAD - User manual, Dematic, Pty. Ltd., Sydney, Australia.

Dunai, L., Hegedus, T., Kaltenbach, L., and Adany, S. (1997). "Experimental and numerical studies on the stability of racking frames." Proc., 5th International Colloquium on the Stability and Ductility of Steel Structures Elsevier Science Ltd 647-652.

EN 15512 (2009). "Steel static storage systems - Adjustable pallet racking systems Principles for structural design." European Committee for Standardization (CEN), Brussels, Belgium.

FEM 10.2.07 (2002). "Version 0.02 - Draft - The Design of 'Drive in' and 'Drive through' pallet racking." Federation Europeenne de la Manutention, Brussels, Belgium.

Freitas, A. M. S., Souza, F. T., and Freitas, M. S. R. (2006). "Theoritical-experimental analysis of industrial storage racks - Drive-in in cold formed steel members." Proc., 
International Colloquium on Stability and Ductility of Steel Structures, IST Press, 373380.

Freitas, A. M. S., Souza, F. T., and Freitas, M. S. R. (2007). "Analysis and behaviour of drive-in storage structures." Proc., 6th International Conference on Steel and Aluminium Structures, 955-962.

Gilbert, B. P., and Rasmussen, K. J. R. (2009a). "Experimental test on steel storage rack components." Research Report R899, School of Civil Engineering, The University of Sydney, Australia.

Gilbert, B. P., and Rasmussen, K. J. R. (2009b). "Finite Element modelling of steel drivein rack structures." Research Report R901, School of Civil Engineering, The University of Sydney, Australia.

Gilbert, B. P., and Rasmussen, K. J. R. (2009c). "Stiffness tests, failure tests and load transfer in steel drive-in storage racks." Research Report R900, School of Civil Engineering, The University of Sydney, Australia.

Gilbert, B. P., and Rasmussen, K. J. R. (2010). "Bolted moment connections in drive-in and drive-through steel storage racks." Journal of Constructional Steel Research, 66(6), 755-766.

Gilbert, B. P., Rasmussen, K. J. R., and Zhang, H. (2009). "Impact tests and parametric impact studies on drive-in steel storage racks." Research Report R903, School of Civil Engineering, The University of Sydney, Australia.

Godley, M. H. R. (2002). "The behaviour of drive-in storage structures." Proc., 16th International Specialty Conference on Cold-Formed Steel Structures, 340-352.

Godley, M. H. R. (2007). "The behaviour of storage racking baseplates." Proc., 6th International Conference on Steel and Aluminium Structures, 433-440.

Hua, V., and Rasmussen, K. J. R. (2006). "The behaviour of drive-in racks under horizontal impact load." Research Report R871, School of Civil Engineering, The University of Sydney, Australia.

Hua, V., and Rasmussen, K. J. R. (2010). "Static friction coefficient between pallets and beam rails and pallet shear stiffness tests." Research Report 914, School of Civil Engineering, The University of Sydney, Australia.

Murray, N. W. (1995). "Stability analysis of drive-in racking storage systems." Proc., International Conference on Structural Stability and Design 189-195.

Pekoz, T., and Winter, G. (1973). "Cold-formed steel rack structures." Proc., 2nd Specialty Conference on Cold-Formed Steel Structures, 603-615. 
RMI (2008). "Specification for the design, testing and utilization of industrial steel storage racks." Rack Manufacturers Institute, Charlotte, U.S.A.

Sajja, S. R., Beale, R. G., and Godley, M. H. R. (2006). "Factors affecting the shear stiffness of pallet rack uprights." Proc., Stability and Ductility of Steel Structures, 365372.

Sajja, S. R., Beale, R. G., and Godley, M. H. R. (2008). "Shear stiffness of pallet rack upright frames." Journal of Constructional Steel Research, 64(7-8), 867-874.

Salmon, M. A., Welch, R. E., and Longinow, A. (1973). "Analysis of drive-in and drivethru storage racks." Proc., 2nd Specialty Conference on Cold-Formed Steel Structures, 617-639.

SEMA (1980). "Code of practice for the design of static rack." Storage Equipment Manufacturers' Association, London, UK.

Zhang, H., Gilbert, B. P., and Rasmussen, K. J. R. (2011). "Drive-in steel storage racks II: Reliability-based design for forklift truck impact." Submitted to ASCE Journal of Structural Engineering. 


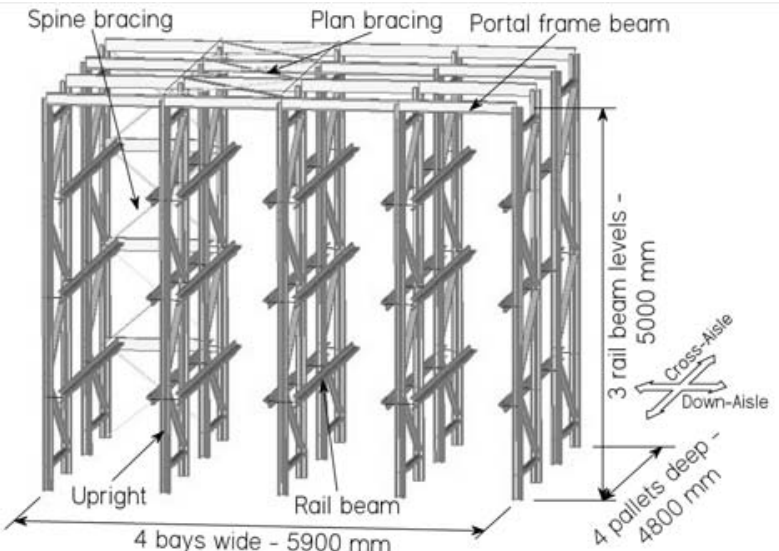

(a)

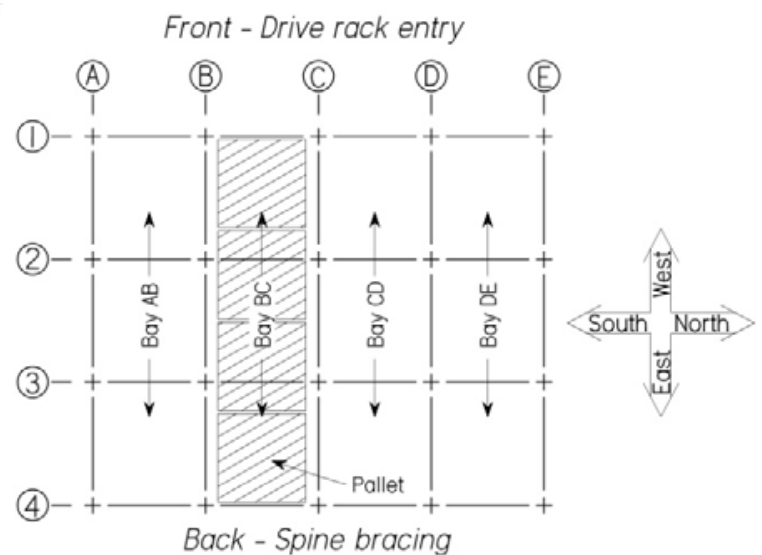

(b)

Figure 1: Tested drive-in rack configuration

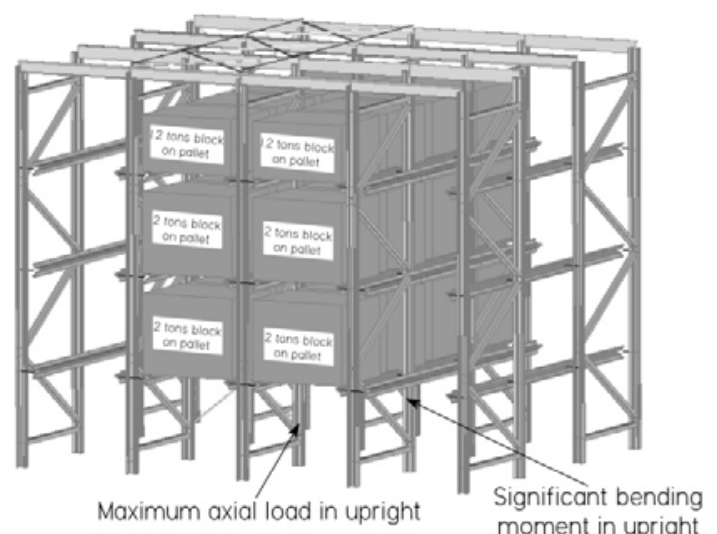

Figure 2: "Fully loaded" drive-in rack configuration

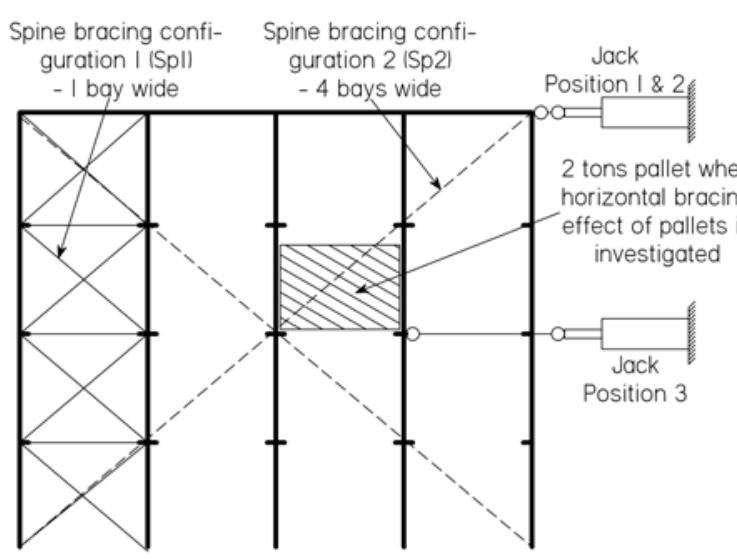

(a)

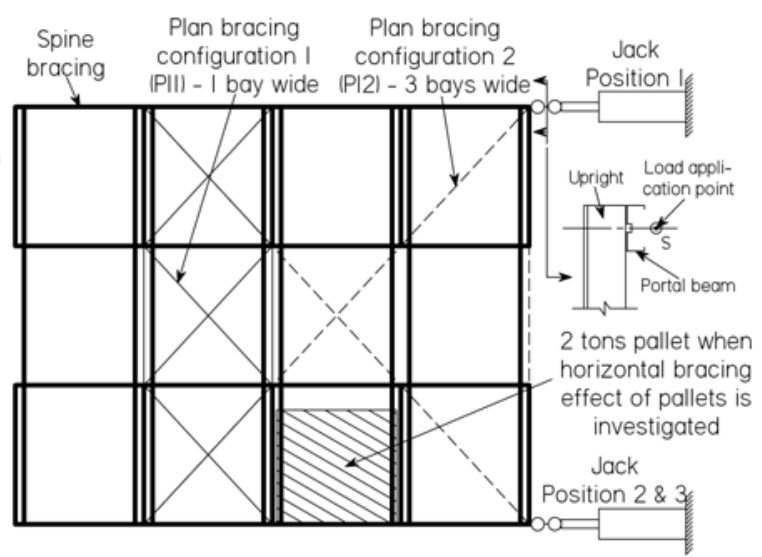

(b)

Figure 3: Bracing configurations and jack positions, (a) front view and (b) top view 


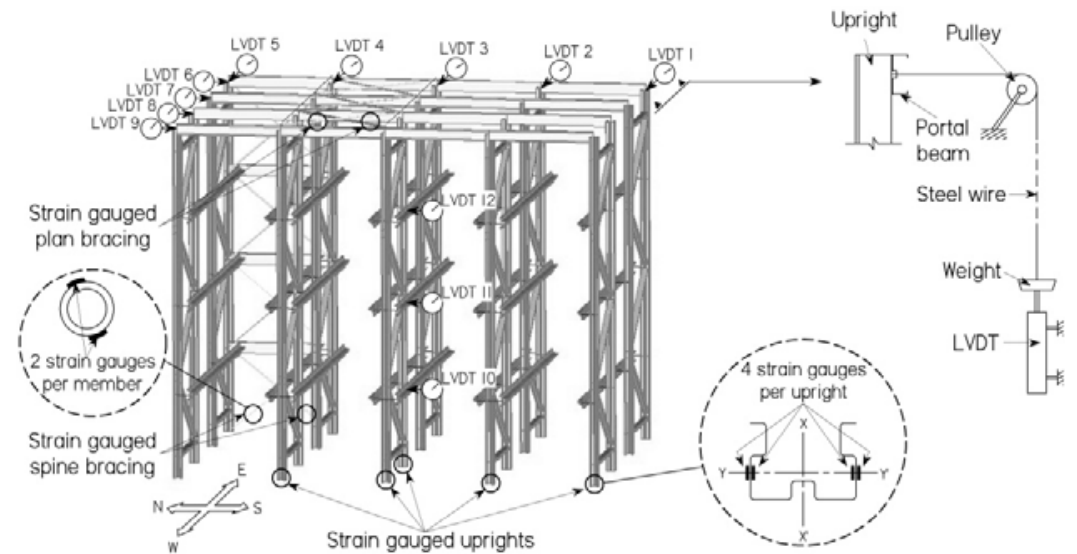

Figure 4: General transducer locations

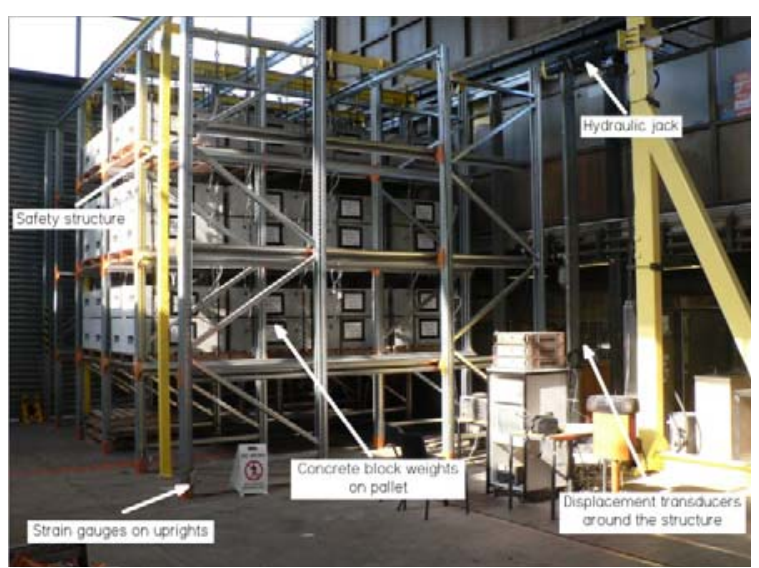

Figure 5: Picture of the test frame (loaded) with jack in position 1 


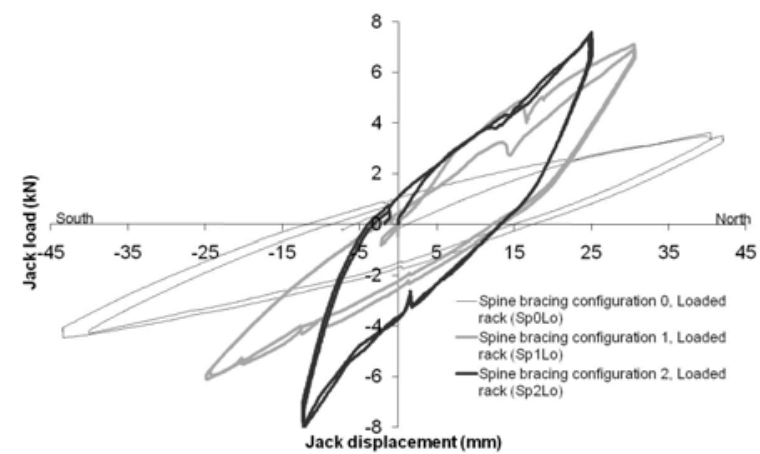

(a) Loaded, position 1

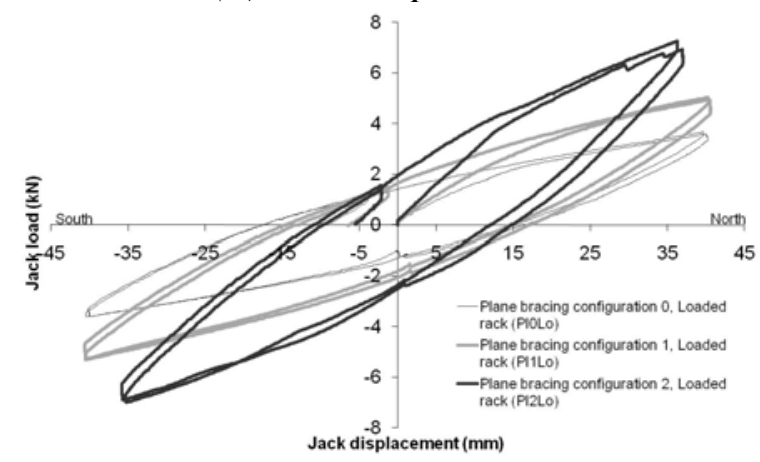

(c) Loaded, position 2

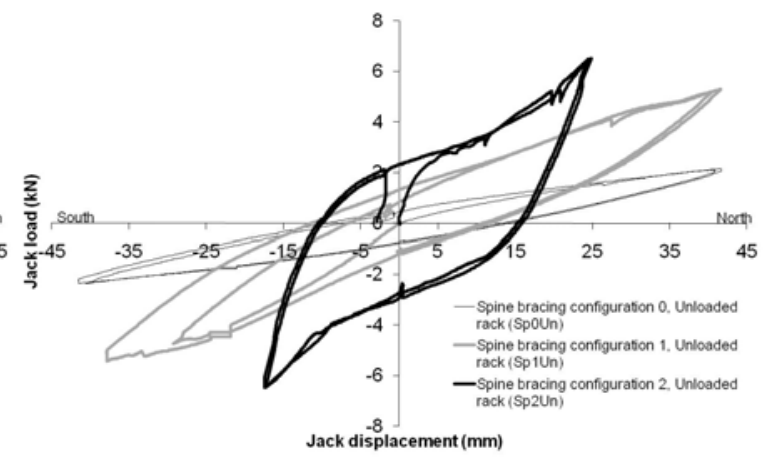

(b) Unloaded, position 1

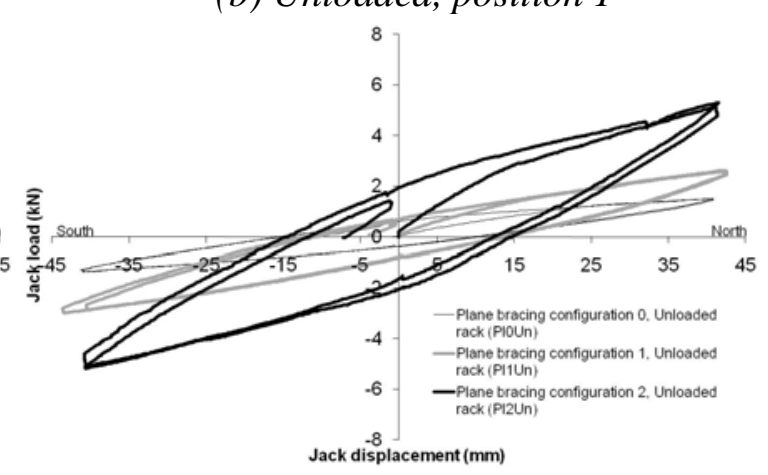

(d) Unloaded, position 2

Figure 6: Relative bracing stiffness for the loaded and unloaded rack with (a), (b) jack in position 1 and (c), (d) jack in position 2 


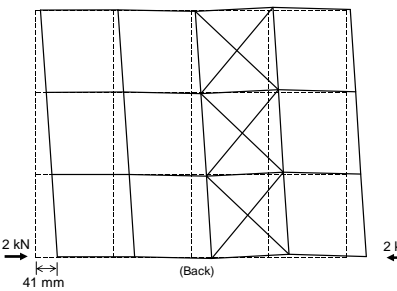

(a)

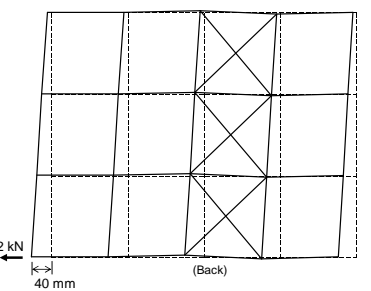

(b)

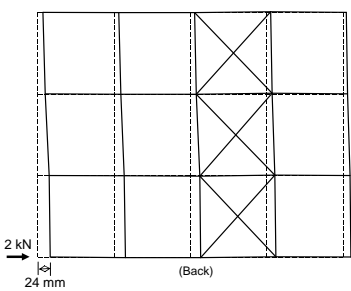

(c)

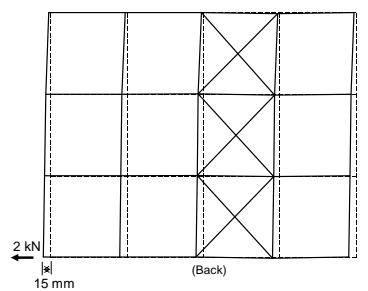

(d)

Figure 7: Drive-in rack behaviour when applying horizontal load with jack in position 1, no spine bracing for (a) and (b) test 'SpOUn', (c) and (d) test 'SpOLo'

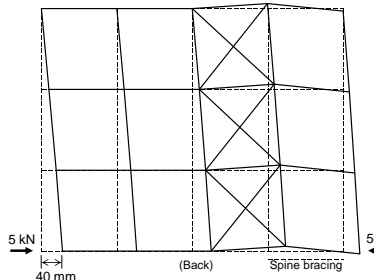

(a)

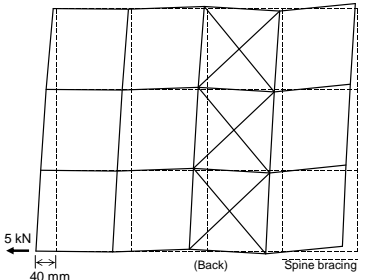

(b)

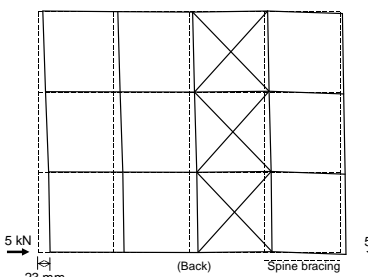

(c)

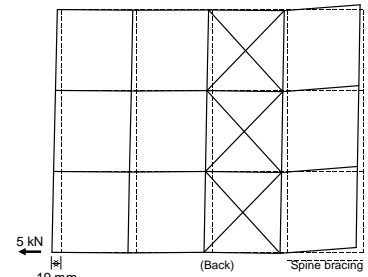

(d)

Figure 8: Drive-in rack behaviour when applying horizontal load with jack in position 1, spine bracing in configuration 1 for (a) and (b) test 'Sp1Un', (c) and (d) test 'Sp1Lo'

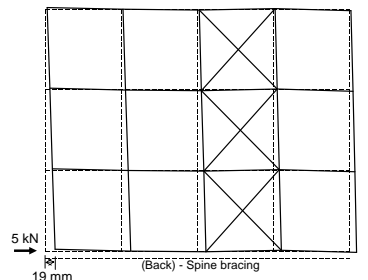

(a)

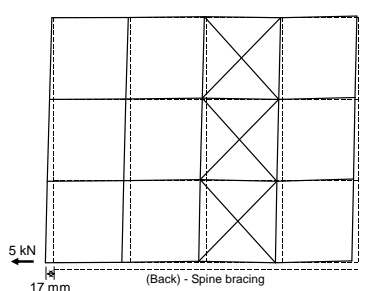

(b)

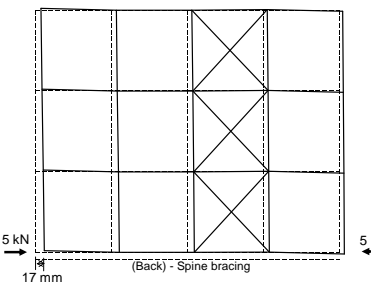

(c)

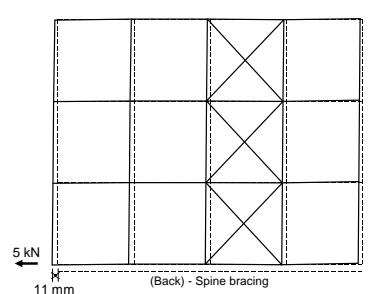

(d)

Figure 9: Drive-in rack behaviour when applying horizontal load with jack in position 1, spine bracing in configuration 2 for (a) and (b) test 'Sp2Un', (c) and (d) test 'Sp2Lo'

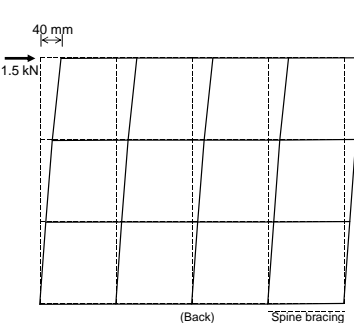

(a)

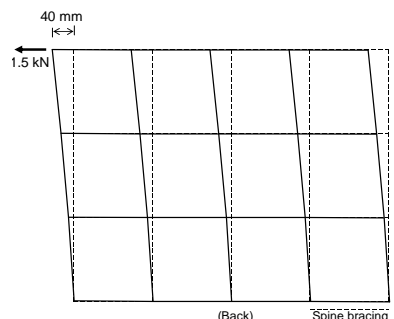

(b)

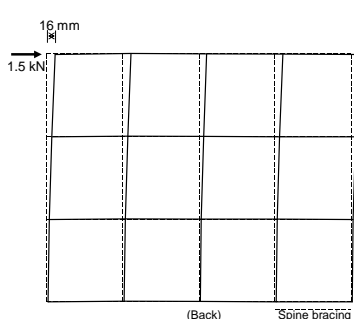

(c)

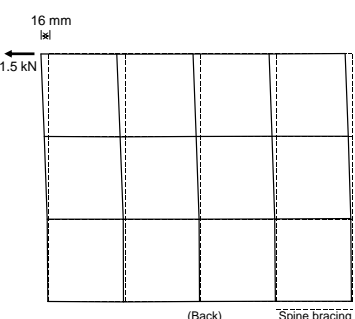

(d)

Figure 10: Drive-in rack behaviour when applying horizontal load with jack in position 2, no plan bracing for (a) and (b) test 'PIOUn', (c) and (d) test 'PIOLo' 


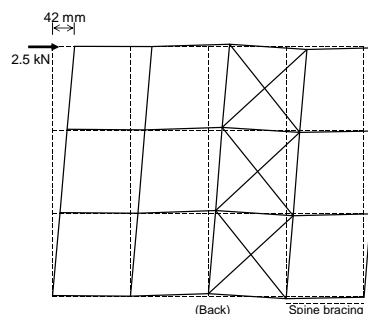

(a)

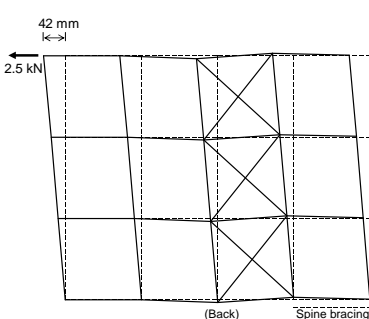

(b)

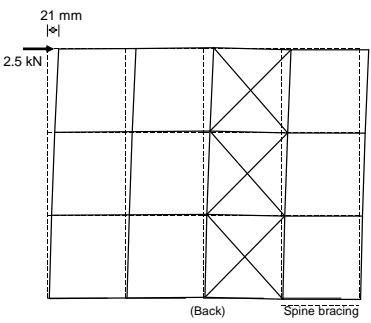

(c)

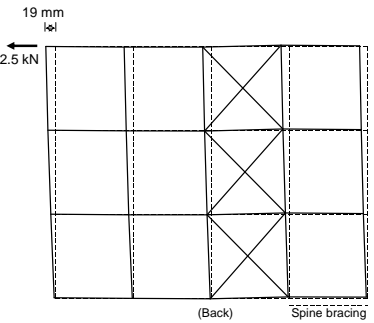

(d)

Figure 11: Drive-in rack behaviour when applying horizontal load with jack in position 2, plan bracing in configuration 1 for (a) and (b) test 'Pl1Un', (c) and (d) test 'Pl1Lo'

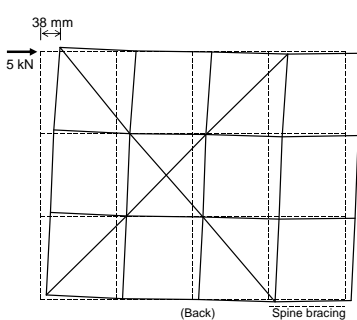

(a)

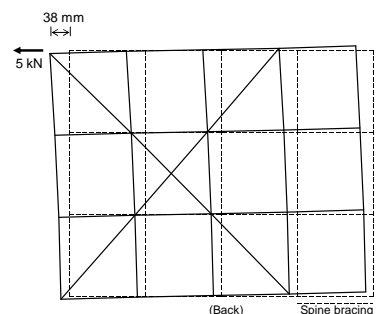

(b)

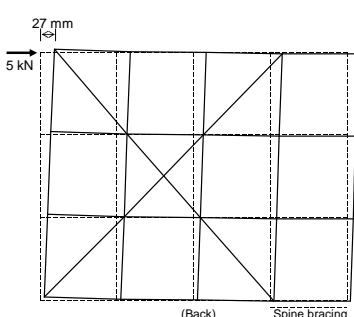

(c)

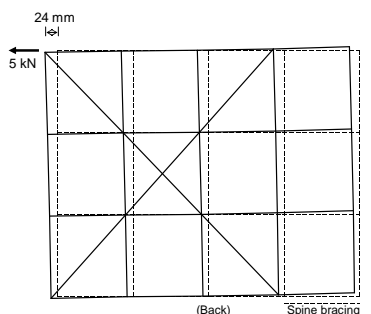

(d)

Figure 12: Drive-in rack behaviour when applying horizontal load with jack in position 2, plan bracing in configuration 2 for (a) and (b) test 'Pl2Un', (c) and (d) test 'Pl2Lo'

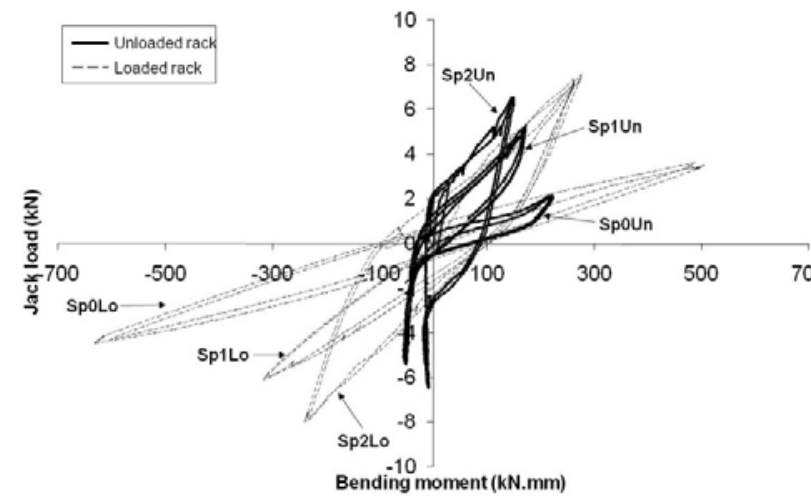

(a)

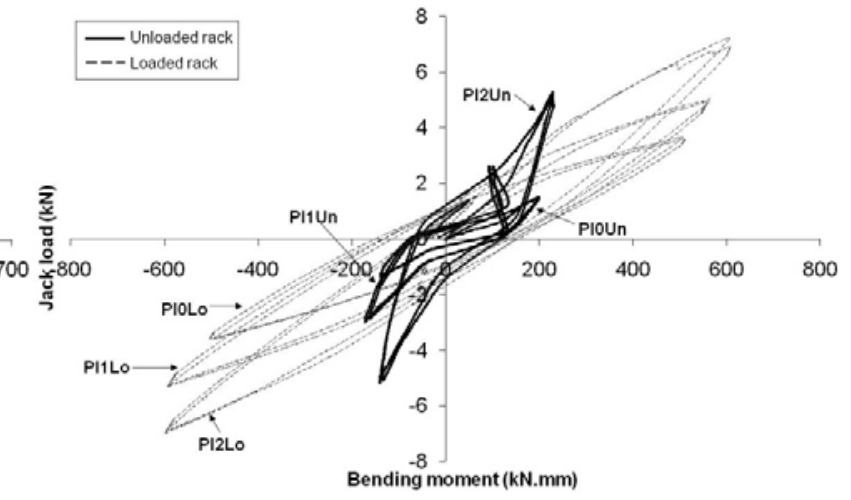

(b)

Figure 13: Variation in bending moment in upright C2 for (a) jack in position 1 and (b) jack in position 2 


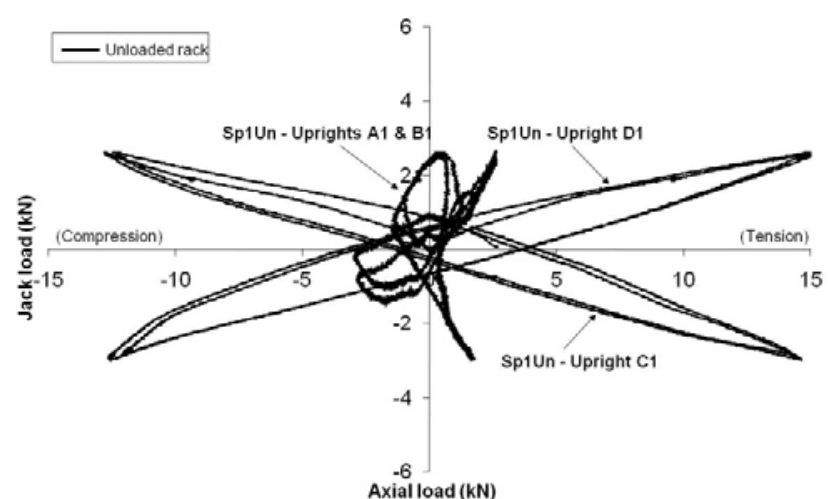

(a)

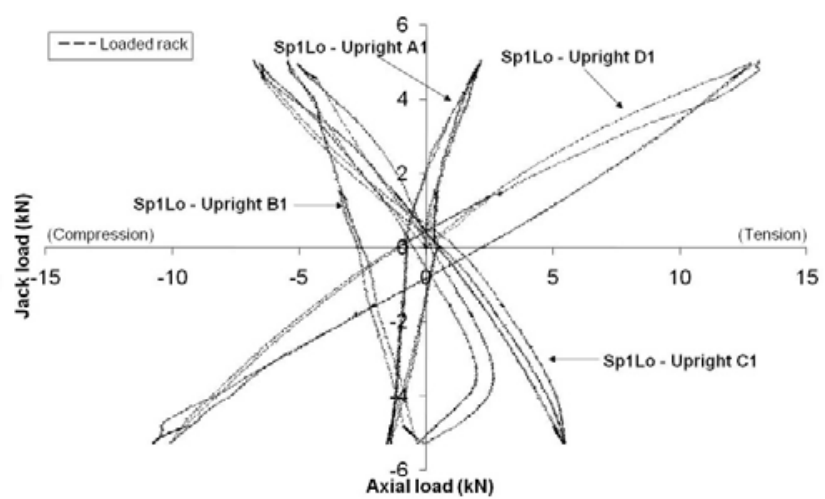

(b)

Figure 14: Variation in axial load from strain gauges for jack in position 2 and plan bracing in configuration 1 for (a) unloaded rack and (b) loaded rack

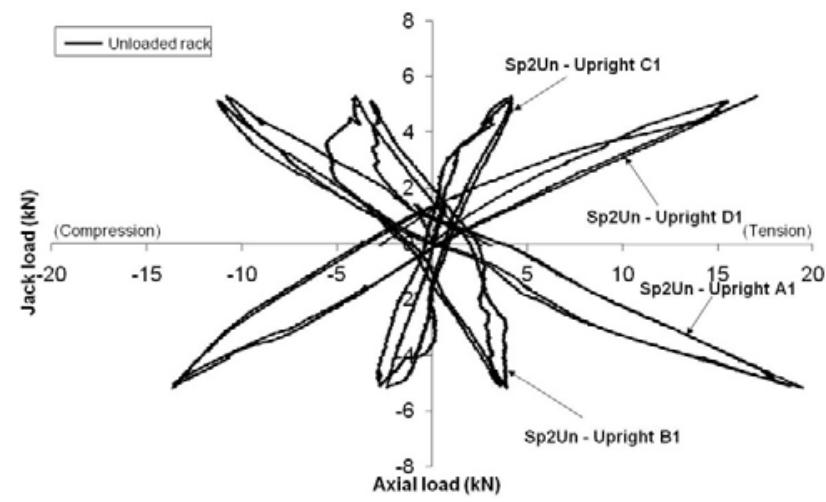

(a)

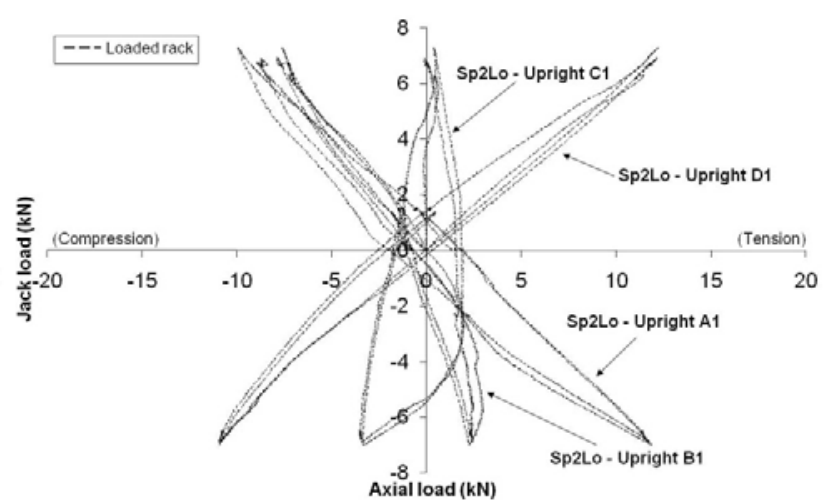

(b)

Figure 15: Variation in axial load from strain gauges for jack in position 2 and plan bracing in configuration 2 for (a) unloaded rack and (b) loaded rack

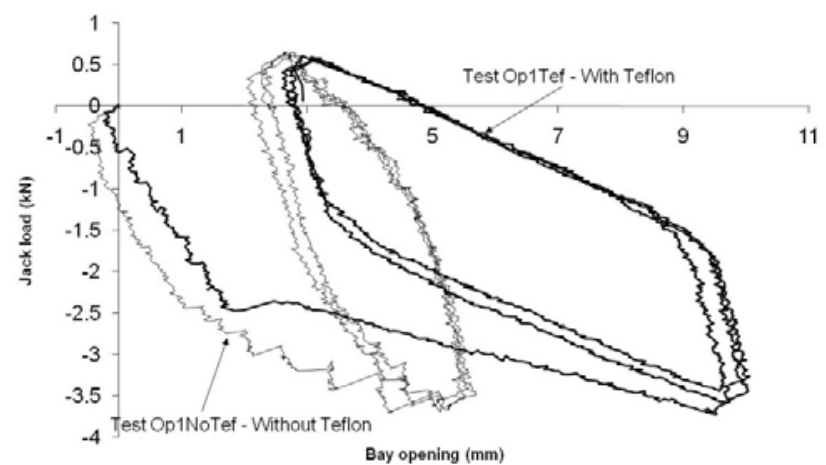

Figure 16: Load Vs bay opening 


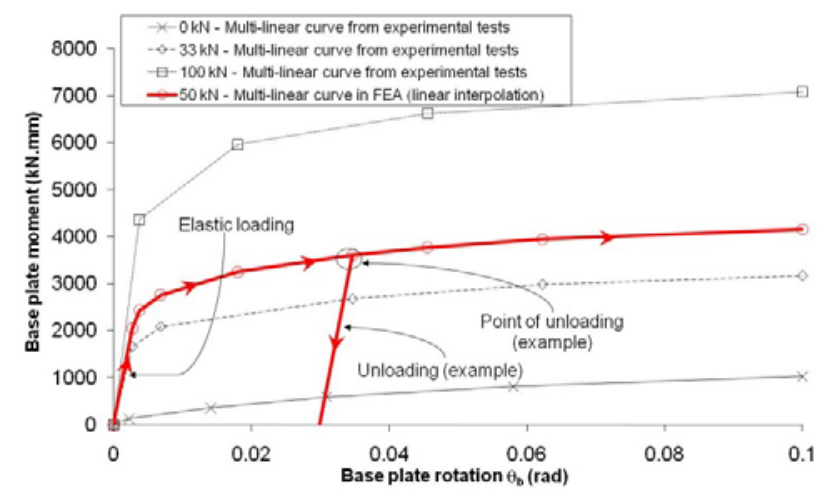

(a)

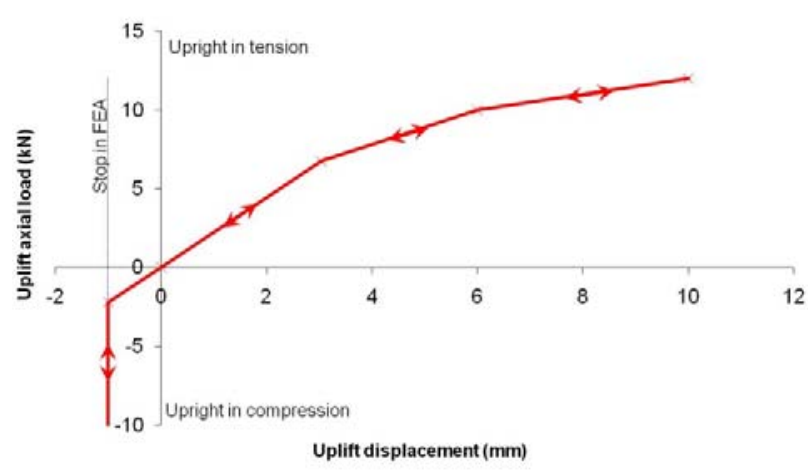

(b)

Figure 17: (a) Typical multi-linear curve used for the base plate rotational stiffness and (b) base plate uplift multi-linear curve

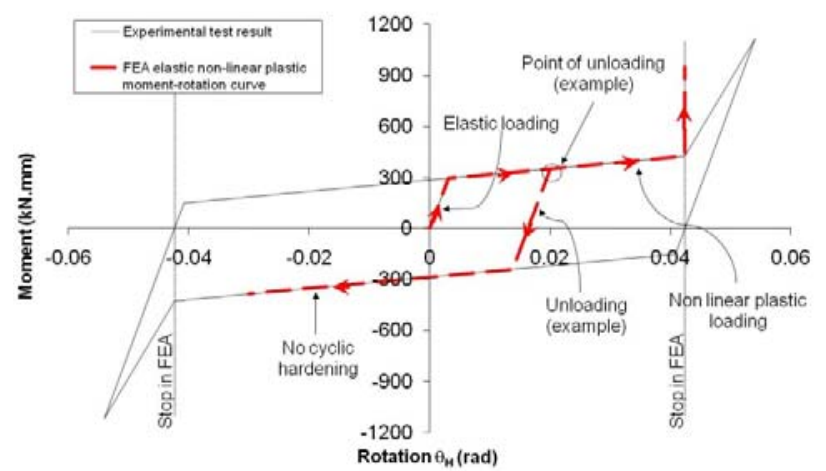

Figure 18: Multi-linear curve used for the portal beam to upright connection

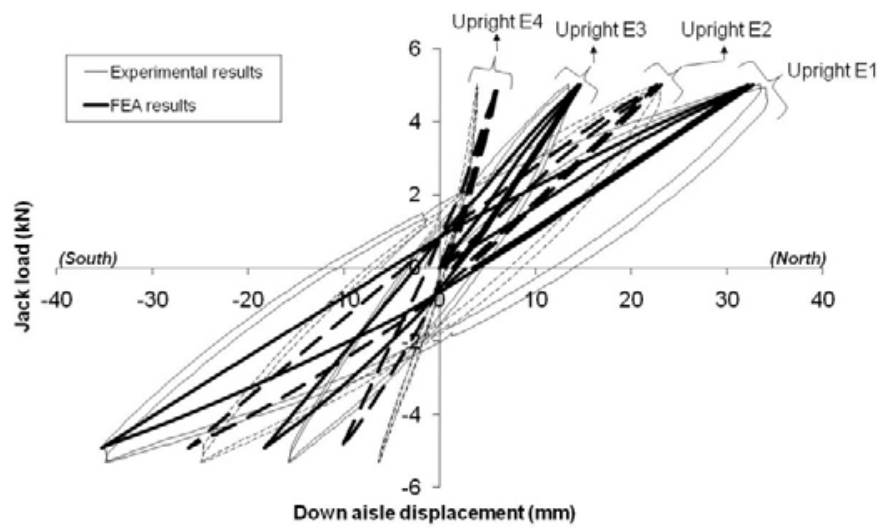

Figure 19: Comparison between experimental and numerical results for down-aisle displacements of uprights E1 to E4 for test 'Pl1Lo' 


\begin{tabular}{llllll}
\hline Member & $\begin{array}{l}\text { Gross } \\
\text { area } \\
\left(\mathrm{mm}^{2}\right)\end{array}$ & $\begin{array}{l}\mathrm{I}_{\text {major axis }} \\
\left(\mathrm{mm}^{4}\right)^{(3)}\end{array}$ & $\begin{array}{l}\mathrm{I}_{\text {minor axis }} \\
\left(\mathrm{mm}^{4}\right)\end{array}$ & $\begin{array}{l}\mathrm{J} \\
\left(\mathrm{mm}^{4}\right)\end{array}$ & $\begin{array}{l}\mathrm{I}_{\text {warping }} \\
\left(\mathrm{mm}^{6}\right)\end{array}$ \\
\hline Upright and cross-aisle plan bracing $^{(1)}$ & 727.9 & $1.328 \times 10^{6}$ & $6.852 \times 10^{5}$ & 780.6 & $2.510 \times 10^{9}$ \\
Frame diagonal bracing $^{(2)}$ & 283.7 & $2.662 \times 10^{5}$ & $9.928 \times 10^{4}$ & 212.8 & $1.337 \times 10^{8}$ \\
Portal beam and hor. spine bracing $^{(1)}$ & 559.1 & $1.746 \times 10^{6}$ & $1.683 \times 10^{5}$ & 672.8 & $1.011 \times 10^{9}$ \\
Diagonal spine and plan bracing $^{(2)}$ & 156.5 & $1.217 \times 10^{4}$ & $1.217 \times 10^{4}$ & 2433.0 & -- \\
Rail beam $^{(1)}$ & 640.8 & $1.449 \times 10^{6}$ & $6.067 \times 10^{5}$ & 771.1 & $4.638 \times 10^{8}$ \\
\hline
\end{tabular}

${ }^{(1)}$ Properties based on measurements or tests

(2) Nominal properties

(3) The major axis of the uprights is the axis of symmetry (aligned with the cross-aisle direction)

Table 1: Main section properties

\begin{tabular}{llllll}
\hline Test label & $\begin{array}{l}\text { Spine } \\
\text { configuration }\end{array}$ & $\begin{array}{l}\text { Plan } \\
\text { configuration }\end{array}$ & $\begin{array}{l}\text { Jack } \\
\text { position }\end{array}$ & $\begin{array}{l}\text { Repeated } \\
\text { test }\end{array}$ & Loading condition \\
\hline Sp1Un / Sp1Lo & 1 & 1 & 1 & Yes & Unloaded / Loaded \\
Sp0Un / Sp0Lo & No spine & 1 & 1 & Yes & Unloaded / Loaded \\
Sp2Un / Sp2Lo & 2 & 1 & 1 & Yes & Unloaded / Loaded \\
Pl1Un / Pl1Lo & 1 & 1 & 2 & Yes & Unloaded / Loaded \\
Pl0Un / Pl0Lo & 1 & No plan & 2 & Yes & Unloaded / Loaded \\
Pl2Un / Pl2Lo & 1 & 2 & 2 & Yes & Unloaded / Loaded \\
Op1NoTef & 1 & 1 & 3 & No & 1 pallet w/o Teflon \\
Op1Tef & 1 & 1 & 3 & No & 1 pallet with Teflon \\
\hline
\end{tabular}

Table 2: Non destructive test configurations 